\title{
Contribución al estudio de la buena fe en el Derecho Privado: a propósito de la renegociación y el incumplimiento de los deberes secundarios de conducta
}

Javier VÁsquez Laguna

Abogado por la Pontificia Universidad Católica del Perú. Postgrado en Gestión de Proyectos Inmobiliarios por la Universidad Peruana de Ciencias Aplicadas.

SUMARIO:

I. Introducción.

II. Análisis general del principio de buena fe.

1. La buena fe como principio general del Derecho.

2. La doble dimensión de la buena fe.

3. "La buena fe no agota su alcance en la oposición de la mala fe".

III. Breve análisis de los efectos de la buena fe durante todo el iter contractual.

1. Etapa precontractual, negociación y celebración.

2. Etapa de ejecución contractual.

3. Etapa post contractual.

IV. El principio de buena fe como límite de la autonomía privada.

V. El principio de buena fe como criterio hermenéutico.

VI. Los deberes secundarios de conducta.
1. El deber de protección.
2. El deber de información.
3. El deber de consejo.
4. El deber de fidelidad.
5. El deber de secreto.
6. El deber de renegociación.

VII. Análisis de la buena fe durante la ejecución del contrato —o sobre el deber de renegociación-.

1. Aspectos generales.

2. Cambio de circunstancias como presupuesto para el nacimiento de la obligación de renegociar.

3. Causas que activan el deber de renegociar.

VIII. Resolución contractual por incumplimiento del deber secundario de conducta de renegociación.

IX. Conclusiones. 


\section{RESUMEN:}

El presente ensayo aborda el estudio del principio de la buena fe, de los deberes secundarios de conducta y los efectos de su incumplimiento. Para ello, se aborda el estudio de la buena fe en su doble dimensión subjetiva y objetiva, como límite de la autonomía privada, así como en su rol de criterio de interpretación y orientador de conductas. A partir de los aspectos antes señalados, se desarrollan los efectos del incumplimiento de los deberes secundarios de conductas y se postula la posibilidad de activar un mecanismo resolutorio por infracción al deber de renegociación..

Palabras clave: principio de buena fe, incumplimiento contractual, deberes secundarios de conducta, obligación de renegociar, derecho privado.

\footnotetext{
ABSTRACT:

This essay approaches the study of the principle of good faith, secondary performance obligations and the effects of non-compliance. For this, the study of good faith is approached in its double subjective and objective dimension, as a limit to private autonomy, as well as in its role of interpretation criterion and performance guide. Based on the aforementioned aspects, the effects of non-compliance of secondary duties of conduct are developed and the possibility of activating a termination mechanism for violation of the renegotiation duty is postulated.

Keywords: good faith principle, contractual non-compliance, secondary performance obligations, obligation to renegotiate, private law.
}

\section{INTRODUCCIÓN}

Poco antes de escribir este breve ensayo, con motivo de una renegociación contractual enmarcada en el contexto de la crisis de la COVID-19', debatíamos con algunos colegas cuál es el rol de la buena fe y los efectos que venía generando la falta de comprensión de esta figura por algunos operadores jurídicos. Discutíamos también si la buena fe, per se, exigía que las partes renegocien los términos contractuales, así como cuáles podrían ser los efectos en un eventual proceso judicial en caso una parte opte por no seguir las exigencias de la buena fe.

El estudio de la buena fe tiene una aplicación práctica en atención al elevado número de conflictos que se han generado, situación que nos lleva a reevaluar la importancia del estudio de algunas figuras del Derecho Civil que son menos estudiadas en épocas de prosperidad económica. Por ello, dada la poca relevancia que nuestro ordenamiento jurídico positivo le ha brindado a la buena fe, no resulta fácil para todos los operadores jurídicos poder definir los alcances de esta figura, al punto de considerarla como algo esotérico y cuya aplicación es más bien intuitiva.

No pretendo aquí abordar cada aspecto y matiz del estudio de la buena fe, más todavía si tenemos en cuenta la amplitud de posturas doctrinales, bastante especializadas y extendidas. El presente artículo pretende otorgar al lector algunas herramientas metodológicas que guíen no solo la ejecución contractual; sino, especialmente, puedan servir de base para las renegociaciones con la finalidad de evitar que una determinada acción que recomendemos a nuestros clientes pueda ser considerada como contraria a la buena fe por un tribunal; o, lo que es lo mismo, poder sustentar adecuadamente la toma de una decisión comercial que se hubiera desarrollado en conjunto con nuestros clientes.

La doctrina colombiana ha sido particularmente rica en el análisis de esta figura jurídica, por lo que no debe sorprender al lector especializado notar que en el desarrollo teórico de este ensayo le otorgo una especial relevancia al aná-

1. Para quienes lean el presente artículo, es preciso anotar que este fue elaborado durante la primera mitad del año 2020, momento durante el cual el virus coloquialmente como COVID-19 obligaba al gobierno a tomar medidas de emergencia, que impedían ejercer muchas actividades comerciales con la consecuente crisis económica y social que ello implica. 
lisis desarrollado por juristas de dicho país, los cuales forman la base del presente estudio.

Igualmente, es preciso indicar que, aun cuando en estas líneas hago mención de la normativa peruana, este trabajo otorga una especial relevancia al análisis doctrinal con la finalidad de que también pueda ser utilizado como marco de referencia para el análisis de otras legislaciones; en este contexto, en una próxima revisión estas notas serán ampliadas en atención a la jurisprudencia peruana.

Asimismo, y reconociendo la importancia de comprender la evolución histórica de las figuras jurídicas estudiadas, debido a la extensión de este estudio además de que es su propósito el brindar herramientas teóricas y metodológicas para la aplicación práctica del principio de buena fe, no realizaremos aquí un repaso histórico de la figura que nos convoca. Queda a cargo de cada lector el profundizar el estudio evolutivo de esta figura para enriquecer el análisis.

Finalmente, si el lector deseara abordar directamente los aspectos relacionados a los deberes secundarios de conducta y las implicancias de su incumplimiento, o los alcances del principio de buena fe durante la etapa de ejecución contractual, puede pasar directamente a la lectura de las secciones VII Y VIII, respectivamente. No obstante, recomiendo la lectura de las secciones restantes para una mejor comprensión de lo que allí se señala.

\section{ANÁLISIS GENERAL DEL PRINCIPIO DE BUENA FE}

Creemos que con acierto se ha señalado que la buena fe es una vía de comunicación del Derecho con la moral'.
La buena fe reviste tantos matices que puede ser entendida como la convicción del proceder correcto, regular y permitido, pero también como confianza en la apariencia, como puede acontecer ante la compra en un establecimiento abierto al público. Asimismo, puede ser entendida como criterio de conducta.

\section{La buena fe como principio general del Derecho.}

Resulta común que los operadores jurídicos señalemos que "los contratos se negocian y ejecutan en base al principio de la buena fe", sin desarrollar esta los alcances de esta afirmación.

Como hemos señalado, la buena fe es un principio general del Derecho. Siendo así, es preciso señalar, cuando menos brevemente, qué entendemos por principio.

El profesor Muñoz Laverde define como principio general del Derecho a aquella proposición cuya verdad se admite sin pruebas, y que es necesaria para servir de base a ulteriores razonamientos. Vale decir, un principio general del Derecho es una verdad fundamental que se admite sin prueba en contrario ${ }^{3}$.

En palabras de Marcelo Laborde, "(...) los principios generales de derecho no tienen la estructura lógica de las típicas normas jurídicas, es decir carecen de un supuesto de hecho suficientemente precisado y una consecuencia jurídica con similar propósito de precisión"4.

La escena iusfilosófica no ha sido ajena al análisis de este principio. Robert Alexy, destacado filósofo del Derecho, considera que los principios son "mandatos de optimización" en virtud de los cuales los sujetos se encuentran obliga-

2. Jesús González Pérez, «El principio general de la buena fe en el derecho administrativo» (discurso, Real Academia de Ciencias Morales y Políticas, 18 de enero de 1983).

3. Sergio Muñoz Laverde, «La buena fe en el derecho privado» (conferencia, Pontificia Universidad Javeriana, 2018).

4. Marcelo Laborde Goñi, «El principio de la buena fe como rector del ejercicio de la función pública»". Revista de Derecho Público, n. 50 (2016): 57. 
dos a ejecutar sus acciones teniendo en cuenta su capacidad fáctica. Igualmente, Ronald Dworkin, otro eximio referente, concibe a los principios por oposición a las reglas. Para este autor, los principios deben de ponderarse en cada aplicación práctica.

En lo personal, coincido con la postura del profesor Carlos Jaramillo, quien, en su tesis doctoral, concibe a la buena fe tanto como un principio general del Derecho como un criterio hermenéutico, así como límite al ejercicio de los derechos subjetivos y fuente generadora de deberes de conducta 5 .

\section{La doble dimensión de la buena fe.}

Es de sumo conocido que la buena fe presenta una doble dimensión; a saber, una dimensión subjetiva y una objetiva.

\subsection{La dimensión subjetiva de la buena fe.}

Desde esta primera dimensión, la buena fe se materializa en la convicción o creencia de que no se vulnera el derecho de terceros en el correcto proceder. Posiblemente el ejemplo más utilizado por quien enseña esta institución sea la figura de quien, creyéndose propietario, que hace suyos los frutos sobre terreno ajeno ${ }^{6}$.

Sin embargo, para hablar de buena fe, no es suficiente una conducta inocente si es que esta es negligente. Se exige un patrón de conducta, manifestada en la dimensión objetiva de la buena fe ${ }^{7}$.

\subsection{La dimensión objetiva de la buena fe.}

En su dimensión objetiva, es un imperativo de conducta, es una norma ${ }^{8}$. En sentido similar opina Marcelo Laborde al señalar que los principios generales del Derecho están dotados de juridicidad, manifestándose como reglas de Derecho9. Esto exige que toda conducta deba ser analizada bajo los alcances de este criterio.

5. Carlos Jaramillo Jaramillo, La doctrina de los actos propios en el ámbito contractual (España: Universidad de Salamanca, 2012), 75.

6. No es este el lugar para desarrollar la relación existente entre la buena fe y su relación con la doctrina de los actos propios o con otras teorías como la teoría de la apariencia, la doctrina del verwirkung alemana, el estoppel anglosajón, el deber de coherencia del derecho francés, el principio de la confianza legítima, o de las sutilezas de su relación con el error creador de Derecho, pues dicho estudio ameritaría un espacio significativamente mayor que este breve ensayo. Puede darse el caso -como en el ejemplo que da mérito a esta nota de pie- que una persona tiene una real y sincera creencia errónea respecto de una determinada situación jurídica y en virtud de aquella creencia realiza determinadas conductas que, no obstante haber incurrido en error, el ordenamiento jurídico considera pasibles de protección y tutela jurídica. Bajo un análisis estrictamente lógico resultaría contrario a la razón otorgar protección jurídica a quien ejecutara determinadas acciones basadas en una falsa representación de la realidad, como es el caso de las adquisiciones a non domino. Sin embargo, en aras de favorecer el tráfico económico y la seguridad jurídica -según la postura dogmática que prefiera el lector- habiendo ponderado los intereses en juego, el legislador le otorga protección a aquella persona. Estas y otras interrogantes son adecuadamente respondidas por las teorías que he señalado al inicio de esta nota. Queda el lector invitado a realizar un estudio sobre este tema, por demás enriquecedor.

7. Arturo Solarte, siguiendo a Diez-Picazo, sostiene que la buena fe subjetiva se ha distinguido entre la concepción psicológica de la buena fe, entendida ésta como creencia o ignorancia del sujeto, y la concepción ética de la misma, noción ésta de origen germánico, según la cual la ignorancia o el error del sujeto sólo serán atendibles en la medida en que su comportamiento no sea culpable o, dicho de otra forma, tales situaciones sólo serán excusables si el sujeto, con una diligencia normal, no hubiera podido superar su apreciación errada de la realidad.

Arturo Solarte Rodríguez, La buena fe contractual y los deberes secundarios de conducta, (Colombia: Universitas, 2004), 287.

8. Sergio Muñoz Laverde, Op. Cit.

9. Marcelo Laborde Goñi, Op. Cit., 59. 
Como veremos en otro apartado, la buena fe despliega sus efectos como un criterio de interpretación objetiva que integra el contenido negocial ${ }^{10} y$, en la legislación peruana, tiene su concretización principalmente en los artículos $168^{11}$ y $1362^{12}$ del Código Civil, aplicables a todo acto jurídico en general y al contrato en particular, respectivamente.

No olvide el lector, que las obligaciones contractuales obedecen no solamente a fuentes autónomas, sino también a fuentes heterónomas.

Bajo esta dimensión, las partes quedan obligadas a ejecutar todo aquello que emana de la naturaleza del negocio jurídico celebrado. $\mathrm{O}$, lo que es lo mismo, las partes deben de ejecutar de buena fe sus acciones, so pena de responder por los daños que se pudieran generar.

Esta dimensión normativa de la buena fe obliga a realizar determinadas conductas cuyo incumplimiento podría, inclusive, habilitar el ejercicio del derecho de resolución del negocio jurídico.

En línea con lo que explica Arturo Solarte, la buena fe objetiva puede ser entendida como como aquel parámetro de conducta que debe ser observado en las relaciones que los particulares establecen ${ }^{13}$.

Conviene precisar que el principio de buena fe debe ser entendido con relación a la conducta dentro de una relación jurídica concreta. Vale decir, el parámetro de conducta esperado no está referido a la conducta que podríamos esperar de la contraparte, sino a la conducta que cabría esperar de una persona común en la misma situación; o, como señala Marcelo Laborde, está referido a la conducta que cabría esperar de una persona corriente, normal, ni santa, ni mala ${ }^{14}$.

\section{3. "La buena fe no agota su alcance en la oposición de la mala fe".}

Me permito utilizar las palabras del profesor Arturo Solarte en el título de este apartado, pues expresa de la mejor forma los alcances de la buena fe. Esta no agota su significado por sola oposición a la mala fe -en tanto conducta rechazada por la sociedad y por el ordenamiento jurídico-, sino que abarca mucho más que ello.

La buena fe implica un actuar honesto, pero también diligente. La buena fe no se agota en la pura ausencia de malicia. La buena fe es mucho más que lo contrario de mala fe.

En palabras del profesor Fernando de Trazegnies:

"(...) la buena fe no puede consistir en la inocencia del ingenuo o del negligente. Si esa persona que alega buena fe no conoció el hecho irregular que se encontraba detrás de la situación, a pesar de que cualquier persona razonable se hubiera dado cuenta de que tras las cortinas existía gato encerrado que maullaba su irregularidad, no estamos ante una situación de buena fe sino de necedad"n5.

10. No debe de confundirse la buena fe como criterio o regla de interpretación objetiva, con la interpretación en su faceta objetiva. Para un rápido léase: Gastón Fernández Cruz, «Introducción al estudio de la interpretación en el Código Civil peruano», Revista Derecho \& Sociedad, Vol. 19 (2002), 146 y ss.

11. Artículo $168^{\circ}$.- El acto jurídico debe ser interpretado de acuerdo con lo que se haya expresado en él y según el principio de la buena fe.

12. Artículo $1362^{\circ}$.- Los contratos deben negociarse, celebrarse y ejecutarse según las reglas de la buena fe y común intención de las partes.

13. Arturo Solarte Rodríguez, Op. Cit.

14. Marcelo Laborde Goñi, Op. Cit., 60.

15. Fernando de Trazegnies Granda, «Desacralizando la buena fe en el derecho», ADVOCATUS, n. 17 (2008): 131. 
Por tanto, es válido sostener que, para que una conducta sea coherente con el principio de buena fe, no será suficiente con acreditar la falta de malicia en la actuación, sino que será necesario acreditar el cumplimiento de, inclusive, otras conductas no establecidas en el contrato pero que forman parte del contenido obligatorio del contrato por aplicación de la ley y del principio de buena fe, que pueden tener similar naturaleza de las obligaciones por ser parte del contenido contractual.

\section{BREVE ANÁLISIS DE LOS EFECTOS DE LA BUENA FE DURANTE TODO EL ITER CON- TRACTUAL}

Como puede asumir el lector, el principio de buena fe se manifiesta en todo el iter contractual. En este sentido, citando al profesor Carlos Jaramillo "(...) dado su inequívoco rol de principio general (...) todo lo permea, todo lo abraza, todo lo irradia, ora directa, ora indirectamente (... $)^{m 6}$.

En su dimensión objetiva la buena fe exige el cumplimiento de determinados deberes, que analizaremos con mayor profundidad en el acápite correspondiente a los deberes secundarios de conducta.

1. Etapa precontractual, negociación y celebración.
Por razones de orden práctico, he considerado unir estas etapas, aun cuando correspondan a momentos distintos.

En todo contrato hay una etapa previa, propuestas, cruce de cartas, envío de información previa, etc. Podemos señalar que la buena fe despliega sus efectos principalmente mediante los deberes de protección y de información.

Un ejemplo de aplicación del principio de buena fe en la etapa precontractual la podemos encontrar si, por ejemplo, un sujeto entabla una negociación sin ánimos reales de celebrar el contrato, con la única intención de obtener información que de otra forma no hubiera podido obtener ${ }^{17}$.

En la legislación peruana, este deber se hace evidente en el artículo 1362 del Código Civil, que establece la exigencia de negociar los contratos de conformidad a las reglas de la buena $\mathrm{fe}^{18}$.

Mientras más cerca de la celebración del contrato estemos, más importancia deberá de prestarse a las causas que justificarían apartarse de las negociaciones, a fin de dicho ejercicio pueda ser considerado acorde con el principio de la buena fe.

Piense el lector en aquellas ocasiones en las cuales solamente una de las partes contratan-

16. Carlos Jaramillo Jaramillo, Op. Cit., 72.

17. En la práctica legal, este riesgo suele limitarse evitarse mediante la celebración de un acuerdo previo en el que se establecen determinados deberes de confidencialidad, limitando el uso de la información que se brindará, así como estableciendo las sanciones aplicables en caso de incumplimiento.

18. Considero importante aquí señalar la crítica que alguna corriente de la doctrina ha señalado. Esta postura crítica sostiene que el artículo 1362 del Código Civil peruano no establece cuáles son las consecuencias del incumplimiento de los deberes que genera la buena fe. En otras palabras, no atribuye expresamente la responsabilidad por el daño que pueda haberse causado. Sin embargo, otro sector de la doctrina peruana ha considerado superada esta objeción al considerar que el artículo 1362 debe ser interpretado conjuntamente con el artículo 1969 del Código Civil, referido al deber de reparación por la generación de un daño en sede extracontractual, enmarcando de esta forma la responsabilidad precontractual queda enmarcada dentro de la responsabilidad aquilina.

Asimismo, cabe señalar que el proyecto de reforma del Código Civil del año 2019 le otorga al principio de buena fe un lugar preponderante, al ser incluido en el Título Preliminar con el siguiente texto: Artículo II.- Buena fe Los derechos se ejercen y los deberes se cumplen conforme a la buena fe. 
tes cuenta con asistencia legal. Y no me refiero únicamente a las relaciones de consumo masivo, sino a contratos que podríamos calificar como típicamente paritarios. Piénsese por un momento en un contrato de arrendamiento entre una cadena de lo que prefiera el lector - cadenas de farmacias, minimarket, etc.- - En este escenario, el principio de buena fe se muestra como una valiosa herramienta de justicia.

La buena fe en la celebración se puede traducir, por ejemplo, en redactar de manera clara el contrato, o bien no abusando de una posición más provechosa o privilegiada.

\section{Etapa de ejecución contractual.}

Los contratos obligan a lo expresamente pactado, pero también obligan a mucho más que eso ${ }^{19}$. Parafraseando a López y López, podemos señalar que, junto con la voluntad creadora de obligaciones, deben de sumarse otras de distinta procedencia que determinan un concurso de fuentes de la reglamentación contractual ${ }^{20}$.

Una aplicación práctica de la buena fe ocurre, por ejemplo, cuando una parte se encuentra ante la posibilidad de que su contraparte no pueda ejecutar la prestación a su cargo y pretende alegar una excepción de incumplimiento o de caducidad de plazo, dependiendo del supuesto negocial ante el cual nos encontremos.
Refiriéndose a la excepción de incumplimiento regulada en el artículo 1460 del Código Civil italiano, Enrico Garbelli nos explica que para que este ejercicio de la autotutela privada pueda ser calificado como legítimo, y por ello no arbitrario ni abusivo, no puede ser ejercido de forma contraria a la buena $\mathrm{fe}^{21}$.

No podemos dejar de mencionar que la legislación italiana se muestra más favorable que la peruana en este aspecto, desde que el texto del artículo 1460 del Código Civil italiano permite a cada uno de los contratantes retener el cumplimiento de su obligación si es que la contraparte no cumple o no ofrece contemporáneamente cumplir la propia, salvo que hayan sido pactados términos diversos para el cumplimiento o que éstos resulten de la naturaleza del contrato ${ }^{22}$.

No obstante que el texto de los artículos 1426 y 1427 del Código Civil peruano, referidos a excepción de incumplimiento y caducidad de plazo, respectivamente, no contienen una exigencia expresa a la buena fe, su aplicación es posible dado que los efectos de la buena fe se despliegan durante todo el iter contractual por ser un principio general del derecho privado.

De esta forma, podemos concebir a la buena fe como un límite a la actuación de la parte que pretende invocar los remedios jurídicos antes expuestos.

19. Sobre el particular, resultará fructífero que el lector pueda dar respuesta propia a dos interrogantes: ¿cómo influye la buena fe en el deber de cumplir la prestación?, y ¿cómo influye la buena fe en la exigencia de la contraprestación?

20. Ángel López y López, «Comentario al artículo 1258 del Código Civil», en Código Civil comentado (España: Thomson Reuters, 2011), 614.

21. Enrico Gabrielli, «La suspensión de la ejecución del contrato en el derecho italiano», Revista de Derecho, n. 9 (2014): 112.

22. En este sentido, atendiendo a lo señalado por Gabrielli, la jurisprudencia italiana ha desarrollado un mecanismo de calificación que han denominado "juicio de proporcionalidad de cumplimiento" por el cual la facultad del deudor de rehusar la ejecución de la prestación a su cargo se encuentra subordinada a la gravedad del incumplimiento de la contraparte. Vale decir, para que sea válido hacer uso de la excepción de incumplimiento será necesario que el incumplimiento de la contraparte revista importancia en relación con los intereses de quien pretende usar el remedio jurídico. 


\section{Etapa post contractual.}

Nos toca abordar ahora a los llamados deberes post contractuales. Siendo la buena fe un principio que afecta todas las conductas, sus efectos alcanzan la etapa post contractual mediante la exigencia de un comportamiento que permita y favorezca la cabal y adecuada terminación de la relación contractual.

Así, por ejemplo, el Tribunal Supremo español estableció que el administrador de una sociedad, cuando ha cesado en sus funciones, debe abstenerse de favorecerse de las oportunidades de negocio que formaban parte del activo de la sociedad de la que formaba parte ${ }^{23}$.

\section{EL PRINCIPIO DE BUENA FE COMO LÍMITE DE LA AUTONOMÍA PRIVADA}

Durante los últimos meses, la santidad de los contratos ha tomado una fuerza no vista en mucho tiempo. Se ha señalado que los contratos deben de ser respetados - casi- sin cuestionamientos. Sin embargo, algunas de las voces muy autorizadas en nuestro medio han señalado los límites de esta doctrina. No debe olvidar el lector que la autonomía privada se ejerce dentro de sus límites, los cuales son las normas imperativas, las buenas costumbres, el orden público, y los principios generales del Derecho sobre el que se inspira el ordenamiento jurídico.
La doctrina acepta de forma general que la buena fe cumple un rol frente a los actos de autonomía privada.

En este sentido, cabe citar a David Ariza y Wilson Giraldo, para quienes

"(...) la autonomía de la voluntad privada, por tanto, no es el único principio fundamental sobre el que descansa la contratación privada, pues existe otro principio de igual jerarquía como la buena fe, y de la sumatoria de ambos debe determinarse la fuerza obligatoria del contrato"24.

Como se desarrollará en el acápite correspondiente a los deberes secundarios de conducta, el principio de buena fe obliga a las partes contratantes a actuar más allá de lo expresamente pactado en el contrato, sirviendo como un estándar bajo el cual se analizarán los alcances del principio pacta sunt servanda. De esta forma, el principio de buena fe evita que los negocios jurídicos se tornen en instrumentos que favorezcan el abuso del Derecho.

\section{EL PRINCIPIO DE BUENA FE COMO CRITE- RIO HERMENÉUTICO}

Como hemos señalado, la legislación peruana es modesta en cuanto a la buena fe se refiere a diferencia de otras legislaciones en donde este principio ha sido desarrollado más ampliamente a nivel doctrinal ${ }^{25}$. Sin embargo, en tanto prin-

23. STS 2012/9007, Sala de lo Civil, Sección Primera, del 3 de septiembre de 2012.

24. David Ariza Cabra y Wilson Giraldo Ramírez, Adquisición del derecho de propiedad por la aplicación del principio de buena fe (adquisiciones a non domino) (Bogotá: Pontificia Universidad Javeriana, 2005), 27.

25. Por el ejemplo, el artículo 1603 del Código Civil colombiano establece que "Los contratos deben ejecutarse de buena fe, y por consiguiente obligan no solo a lo que en ellos se expresa, sino a todas las cosas que emanan precisamente de la naturaleza de la obligación, o que por ley pertenecen a ella".

En similar sentido, el artículo 1546 del Código Civil chileno señala que "Los contratos deben ejecutarse de buena fe, y por consiguiente obligan no sólo a lo que en ellos se expresa, sino a todas las cosas que emanan precisamente de la naturaleza de la obligación, o que por la ley o la costumbre pertenecen a ella".

Igualmente, el artículo 1258 del Código Civil español precisa que "Los contratos se perfeccionan por el mero consentimiento, y desde entonces obligan, no sólo al cumplimiento de lo expresamente pactado, sino también a todas las consecuencias que, según su naturaleza, sean conformes a la buena fe, al uso y a la ley". 
cipio, la buena fe no precisa de un desarrollo legislativo para que desarrolle plenamente sus efectos.

Como puede el lector suponer, los contratos contienen dispositivos diversos y su interpretación debe de ser realizada según parámetros de conducta ${ }^{26}$. Vale decir, los negocios jurídicos se celebran con el fin de producir unos determinados efectos que son intencionalmente queridos por las partes ${ }^{27}$.

Se ha señalado que resulta imposible:

"(...) contemplar la totalidad de eventos que se pueden presentar en la ejecución de una relación contractual, ni establecer, de antemano, las soluciones a toda posible controversia. Dada la citada circunstancia, debe acudirse a otras fuentes de "reglamentación contractual", éstas sí heterónomas, con las cuales se podrá integrar el contenido de la regulación que habrá de regir las relaciones de las partes. A través de este procedimiento se puede hallar el "contenido implícito" del contrato"28. $^{2}$.

Para Emilio Betti, la buena fe es fuente objetiva de integración contractual, en tanto que a los contratantes les es exigible determinados deberes de conducta derivados de la necesidad de dar al negocio jurídico cumplimiento de acuerdo con la finalidad perseguida por las partes, debiendo hacer aquello necesario para que la contraparte obtenga un resultado útil de la prestación debida ${ }^{29}$.
Como puede notarse, la buena fe exige un estudio profundo de la interpretación. Sin embargo, no es este el lugar para desarrollar este apartado. Baste señalar que la interpretación bajo los alcances de la buena $\mathrm{fe}^{30}$ implica enriquecer el haz de derechos y deberes surgidos de la simple manifestación de los contratantes, con aquéllos que la ley o la buena fe incorporan al contrato. Dichos deberes, a pesar de "activarse" por fuentes ajenas al texto contractual, no dejan de ser derechos y deberes contractuales. El producto final es un contrato con un contenido complementado, enriquecido en su contenido, por aplicación del proceso de integración. Por ello, coincido con Solarte, al señalar que debemos de referirnos a "buena fe integradora" y no de "buena fe creadora"31.

\section{LOS DEBERES SECUNDARIOS DE CON- DUCTA}

Aquellos lectores interesados en el Derecho Civil no deberían tener cuestionamientos sobre el hecho que la buena fe exige el cumplimiento de los llamados deberes secundarios de conducta, que han dado mérito al desarrollo teórico de grandes exponentes de este campo del conocimiento.

No es este breve ensayo el lugar adecuado para desarrollar a profundidad los fundamentos teóricos que sustentan la existencia de los deberes secundarios de conducta, fundamentos que —además- considero han sido esbozado en las líneas precedentes y que permitirán al lector realizar un estudio particular de los mismos.

26. El Código Civil peruano regula en sus artículos 168, 169, 170 y 1362, cuatro criterios o reglas de interpretación, a saber: (a) interpretación conforme a la voluntad declarada y común intención de las partes; (b) interpretación conforme a la buena fe; (c) interpretación sistemática; e, (d) interpretación funcional o finalista.

27. Arturo Solarte Rodríguez, Op. Cit., 291.

28. Arturo Solarte Rodríguez, Op. Cit., 291.

29. Citado por Arturo Solarte Rodríguez, Op. Cit., 301.

30. En tanto criterio de interpretación, valga la precisión.

31. Arturo Solarte Rodríguez, Op. Cit., 302. 
Sin embargo, si considero importante realizar exponer brevemente estos deberes, en el entendido que muchos operadores jurídicos ajenos al campo civil pueden tener algunas dudas sobre sus alcances.

En este aspecto, debe notar el lector que, en virtud de la buena fe, los contratos no solo obligan a lo que se expresa textualmente, sino también a todo aquello que emana de la naturaleza de la obligación, que le dan contenido, que son su razón de ser.

En esta línea de pensamiento, no se atiende a las exigencias de la buena fe si únicamente se atiende al cumplimiento literal de los compromisos asumidos en los términos estrictamente convenidos, sino que su texto exige adecuaciones para que se satisfaga el programa negocial que las partes han establecido $y$, con ello, los intereses individuales de las partes.

En palabras de Martha Neme:

"(...) la buena fe obliga no solo a lo fijado en la convención y a los cuidados generales usuales entre personas honorables, sino a todas aquellas prestaciones accesorias que las circunstancias que rodean el negocio en cada momento vayan poniendo de manifiesto, con independencia de que hayan o no sido pactadas expresamente ${ }^{1 / 32}$.

Decíamos que el principio de buena fe determina la exigencia de los deberes secundarios de conducta que se integran al contenido contractual. Siendo así una fuente de obligaciones cuyo incumplimiento habilita el uso de un mecanismo resolutorio.

A continuación, revisamos los deberes adicionales de conducta de conocimiento más extendido, pero nos explayaremos en el que da mérito al presente ensayo, el deber de renegociación.

\section{El deber de protección.}

Este deber consiste en evitar que los intereses de la contraparte sean lesionados, ya sea intereses personales o patrimoniales.

\section{El deber de información.}

En virtud de este deber, las partes están obligadas a suministrarse mutuamente información suficiente, objetiva, clara y oportuna, que ayudará a la toma de decisiones.

\section{El deber de consejo.}

La razón de este deber radica en que el consejo sincero de la contraparte ayudará a evaluar adecuadamente los aspectos favorables y desfavorables de una situación, a fin de que la parte que recibe la información pueda tomar la decisión que mejor convenga a sus intereses, según su particular punto de vista. Este deber es especialmente importante en el rubro de servicios profesionales, piénsese en las actividades de los abogados. Finalmente, muchas decisiones deberán de ser tomadas por los clientes, sin embargo, es necesario que sea el experto en leyes quien pueda orientar y aconsejarlo para una adecuada toma de decisión.

\section{El deber de fidelidad.}

El deber de fidelidad puede ser comprendido desde sus manifestaciones concretas. Piénsese en un contrato de mandato, el mandatario está obligado a ejecutar completamente la prestación y deberá de privilegiar los intereses de la persona por cuya cuenta actúa, encontrándose prohibido de sostener relaciones con personas que puedan ocasionar conflictos de intereses con los del mandante.

\section{El deber de secreto.}

Por el deber de secreto, ambas partes quedan

32. Martha Neme Villarreal, «El principio de buena fe en materia contractual en el sistema jurídico colombiano», Revista de Derecho Privado, n. 11 (2006): 90. 
obligadas a no divulgar, publicar o utilizar información propia de una relación para obtener una ventaja injusta frente a la otra, so pena de indemnizar los perjuicios que la violación de dicho deber de abstención ocasione. Nuevamente, queda aquí muy claro el vínculo con algunos servicios profesionales, piénsese especialmente en servicios de asesoría financiera.

\section{El deber de renegociación.}

En opinión del suscrito, este es uno de los deberes exigidos por la buena fe, siendo necesario su estudio y desarrollo en un contexto de crisis en el que nos encontramos.

Los deberes secundarios de conducta representan la concretización de la buena fe $y$, en lo referido a la etapa de ejecución contractual, conllevan la obligación de renegociar términos contractuales en determinadas situaciones.

Eugenio Valladares concibe la idea que existe cierta similitud entre los efectos generados por aplicación del fraude a la ley, y los efectos generados por aplicación de la buena fe a las conductas que la contravengan ${ }^{33}$, con los consecuentes efectos de ineficacia que ello conllevaría.

Ya hemos dicho que es un límite al principio de la autonomía privada y es un criterio orientador de conducta. La intangibilidad de los contratos se fundamenta en el principio de autonomía privada y la máxima res inter alios acta. Los principios se ponderan, y el principio de buena fe exige que los términos económicos sean renegociados si existe un criterio objetivo, como podría ser la pérdida del valor de la contraprestación.

Debido a su importancia, este deber será analizado en la sección VII.
VII. ANÁLISIS DE LA BUENA FE DURANTE LA EJECUCIÓN DEL CONTRATO -O SOBRE EL DEBER DE RENEGOCIACIÓN-

\section{Aspectos generales.}

Como explica Neme Villarreal, la buena fe posee un efecto integrador del contrato,

"(...) en virtud del cual no se hace necesario pactar la buena fe para que los efectos derivados de la misma operen sobre todo contrato, sea mediante la imposición de reglas no previstas por las partes o mediante la restricción o modificación de las estipulaciones contractuales o del ejercicio abusivo de los derechos ${ }^{134}$.

La Corte Constitucional colombiana ha establecido en su Sentencia T-295/99 lo siguiente:

"Un tema jurídico que tiene como sustento el principio de la buena fe es el del respeto al acto propio, en virtud del cual, las actuaciones de los particulares y de las autoridades deberán ceñirse a los postulados de la buena fe. Principio constitucional, que sanciona como inadmisible toda pretensión lícita, pero objetivamente contradictoria, con respecto al propio comportamiento efectuado por el sujeto. Se trata de una limitación del ejercicio de derechos que, en otras circunstancias podrían ser ejercidos lícitamente; en cambio, en las circunstancias concretas del caso, dichos derechos no pueden ejercerse por ser contradictorias respecto de una anterior conducta, esto es lo que el ordenamiento jurídico no puede tolerar, porque el ejercicio contradictorio del derecho se traduce en una extralimitación del propio derecho" el subrayado es nuestro-.

El principio de buena fe impone recíprocamente a los contratantes la obligación de cooperar para

33. Eugenio Valladares Bonet, «La inobservancia del deber de buena fe como causa de incumplimiento contractual» (trabajo de fin de máster, Universidad Complutense de Madrid, 2014), 59.

34. Martha Neme Villarreal, Op. Cit., 88. 
que todos ellos alcancen los intereses concretos que se propusieron al momento de contratar, de modo tal que se honre el programa contractual y evitar la frustración de esos intereses ${ }^{35}$.

En la etapa de ejecución de un contrato debidamente perfeccionado, la buena fe contractual hace surgir un catálogo de deberes de conducta que como pueden ser el de fidelidad, el de consejo, el de secreto, entre otros. Estos deberes deberán analizarse de acuerdo con la naturaleza de la respectiva relación, ampliando los deberes contractualmente asumidos por cada parte para con ello realizar el interés contractual de la otra parte ${ }^{36}$.

Los deberes secundarios de conducta tienen la calidad de ser exigibles, no obstante que no hayan sido previstos expresamente como obligaciones dentro del contrato ${ }^{37}$. No debe de olvidar el lector que la buena fe no solo implica cumplir con las obligaciones expresamente comprometidas, sino que también exige que dicho cumplimiento y en la exigencia del cumplimiento de la contraprestación no se genere ningún daño a la contraparte.

\section{Cambio de circunstancias como presu- puesto para el nacimiento de la obliga- ción de renegociar.}

Como habíamos señalado, las partes en uso de la autonomía de la voluntad han regulado una relación jurídica determinada, habiendo considerado determinadas situaciones como elementos de toma de decisión. Piénsese, por ejemplo, en una empresa comercializadora de ropa que ha arrendado un local comercial en un concurrido centro comercial por un plazo de 10 años pactando una renta mensual de $\$ 1,000.00^{38}$. Esta empresa ha acordado dichas condiciones económicas habiendo realizado un análisis costo-beneficio, considerando que sus ventas esperadas por el uso de ese determinado local significarían flujos suficientes para poder cumplir con el pago.

La afectación económica causada por los efectos de la COVID-19 ha generado que los locales no sean aptos - cuando menos temporalmente- para satisfacer las expectativas económicas de la empresa dedicada al retail. En este escenario cabe preguntarse si la exigencia del pago de la renta pactada es conforme al principio de la buena fe, ¿acaso dicha exigencia satisfaría los intereses de ambas partes? No cabe duda de que satisfaría los intereses del propietario, pero no de una empresa dedicada al retai ${ }^{\beta 9}$.

Como puede observar el lector, puede acontecer un fraccionamiento de la relación sinalagmática, en este caso por la disminución del valor de la contraprestación pues el local no es apto para generar los flujos esperados. Vale decir, si dichas condiciones fueran las que existieran al momento de celebrar el contrato, las par-

35. Eugenio Valladares Bonet, Op. Cit., 58.

36. Arturo Solarte Rodríguez, Op. Cit., 289-290.

37. En palabras de López y López, Ángel, “(...) la operatividad específica de los deberes derivados de la buena fe consiste precisamente en su exigencia, aunque ni la ley ni la voluntad de los sujetos de una relación jurídica los hayan contemplado expresamente (...)".

Ángel López y López, «Comentario al artículo 1258 del Código Civil» en Código Civil comentado, 615.

38. El ejemplo anterior es una reducción de la realidad, por cuanto en este tipo de contratos es común establecer un monto de renta fija y un monto de renta variable pagado en función de los ingresos obtenidos por las ventas en dicho local.

39. Sin embargo, este solo hecho no implica de manera automática que se deba de negociar los términos contractuales, pues deberá de atenderse a otros elementos, como el régimen de distribución de riesgos y responsabilidades que ha sido acordado. 
tes jamás hubieran contratado, o lo hubieran hecho en términos manifiestamente distintos.

No olvidemos que el principio de buena fe exige no hacer más gravoso el cumplimiento de las obligaciones de la contraparte, lo que implica no exigir el cumplimiento de una obligación si ello resulta de sumo complejo en un contexto de crisis. Debemos reconocer que, cuando menos, el principio de buena fe implica que el propietario acepte evaluar un posible aplazamiento en el pago sin penalidades.

Habrá que analizar en cada caso cuáles han sido las condiciones o presupuestos por los cuales las partes contrataron de una determinada forma, y si es que se ha establecido algún mecanismo de asignación de responsabilidad del riesgo.

Finalizamos este apartado dejando sentado que no nos referimos a una exigencia de celebrar nuevos términos contractuales, sino a la exigencia de reevaluarlos y entablar una negociación "de buena fe" 40 .

\section{Causas que activan el deber de renegociar.}

Habiendo quedado sentado que el deber de renegociación es un deber secundario de conducta y que su nacimiento se genera ante situaciones que modifiquen los presupuestos fracturando el equilibrio sinalagmático, queda por tarea desarrollar las causas habilitantes del nacimiento de este derecho.

En principio, será necesario - vía criterios hermenéuticos que el operador jurídico deberá saber utilizar- determinar cuáles fueron los elementos que las partes tomaron en cuenta para la celebración del contrato en determinadas condiciones comerciales y que deban de ser atendibles por haber formado parte de los intereses en juego, sea por expresa mención de las partes o por usos y costumbres del mercado en el tipo contractual bajo escrutinio. No serán atendibles situaciones particulares que no fueron expresadas y que no son parte del contenido natural del tipo negocial, por cuanto nuestro sistema se ha acogido a la teoría declaracionista ${ }^{41}$.

Ante eventos de dimensiones semejantes a la pandemia que actualmente atraviesa el planeta entero, resulta sensato sostener que las condiciones económicas que dieron mérito a la celebración del contrato han variado al punto de exigir que se cumpla con renegociar los términos contractuales en estricto cumplimiento del principio de buena fe.

Finalmente, debemos anotar que, para que nazca el deber de renegociación, es necesario que el cumplimiento de una obligación pactada resulte lesivo para la parte que deba de cumplirla y, por ello, la exigencia de su cumplimiento no puede ser tolerada por el ordenamiento jurídico.

La exigencia de modificación de las prestaciones para el restablecimiento del equilibrio de la relación sinalagmática cuenta ya con otros mecanismos de protección, como la excesiva onerosidad en la prestación ${ }^{42}$. En este sentido, no encuentro objeción conceptual para que la buena fe no cuente con efectos similares; es decir, servir como mecanismo para el restablecimiento del equilibrio de la relación sinalagmáti-

40. En este caso, es usado este término de modo coloquial.

41. Sobre el particular, véase: (a) Carmen Arana Courrejolles, «La interpretación del acto jurídico en el Código Civil peruano de 1984», Thēmis, n. 9 (1987); (b) Juan Espinoza, Acto jurídico negocial (Lima: Instituto Pacífico, 2017); (c) Gastón Fernández Cruz, «Introducción al estudio de la interpretación en el Código Civil Peruano», Derecho \& Sociedad, n. 19 (2002); y, (d) Lizardo Taboada Córdova, Acto Jurídico, Negocio Jurídico y Contrato (Lima: Grijley, 2019).

42. Cfr.: Javier Vásquez Laguna, «Apuntes para una teoría unificada de la excesiva onerosidad de la prestación» Linkedln, 13 de abril de 2020, https://www.linkedin.com/pulse/apuntes-para-una-teor\%C3\%ADa-unificada-de-la-excesiva-en-vasquez-laguna/. 
ca mediante la exigencia de negociación de las obligaciones contractuales.

Sin embargo, existe una sutileza que no puede dejar de atenderse. El principio de buena fe no puede servir para desatender -o pretender cambiar - el régimen de asignación de riesgos y responsabilidades que pudieran haber pactado las partes. No es una carta en blanco que habilite al cambio de asunción de riesgo. Por ello, el intérprete deberá atender con mucho cuidado a todos los criterios hermenéuticos, a fin de poder desentrañar el contenido negocial $y$, solo luego de ello, poder analizar si resulta aplicable el deber secundario de conducta de renegociación.

Con cargo a futuros desarrollos, considero que para el nacimiento del deber de renegociación es preciso la existencia de tres requisitos:

a) Fractura del equilibrio sinalagmático, sea por dos vías:

i. Por el incremento de la prestación; o,

ii. Por el decremento de la contraprestación ${ }^{43}$.

b) Que esa fractura sea consecuencia de la situación externa, no propia del negocio, pues eso es propio del riesgo asumido por las partes.

c) El desequilibrio debe estar referido al elemento objetivo de la relación contractual, y no debe de referirse a situaciones subjetivas. Atender a esto sí podría llevarnos a desatender la propia razón del contrato, el cual es el establecimiento y asignación de riesgos entre las partes.

d) Que la exigencia de cumplimiento cause un daño intolerable.

e) Inexistencia de un régimen de asignación de riesgos y responsabilidades sobre el particular.
No cabe duda que será preciso ponderar el principio de buena fe con otros principios generales del Derecho, y particulares del Derecho Civil, como por ejemplo el de autonomía privada, que lamentablemente ha sido llevado cual estandarte durante los últimos tiempos.

\section{RESOLUCIÓN CONTRACTUAL POR IN- CUMPLIMIENTO DEL DEBER SECUNDA- RIO DE CONDUCTA DE RENEGOCIACIÓN}

Iniciaba este breve ensayo explicando al lector que el desarrollo de estas notas respondía al deseo de otorgar algunas herramientas metodológicas para responder a la pregunta de cuáles son los efectos del incumplimiento de la buena $\mathrm{fe}$, es decir, si es posible que el incumplimiento de los deberes secundarios de conducta habilite el uso de un remedio jurídico como lo es la resolución contractual. Mi opinión, como puede verse, es que resultaría posible la resolución contractual por incumplimiento del deber de renegociar, o por su cumplimento contrario al espíritu de la buena fe.

Reitero que no se trata de una obligación de resultados, sino de medios, si se prefiere utilizar esta distinción. No debe de entenderse como una exigencia de establecer un programa negocial nuevo, acorde a la nueva situación. Sino de realizar dicha acción atendiendo a las exigencias del principio de buena fe.

El deber de renegociación es un deber secundario de conducta que se integra al contenido negocial. Por ello, su incumplimiento debe ser tratado como el incumplimiento de cualquier otro deber secundario de conducta durante la etapa de ejecución contractual y que, para estos efectos, vale equipararlo a una obligación.

En palabras de Martha Neme:

"(e)s por virtud de este carácter normativo del principio que la transgresión de la bue-

\footnotetext{
43. Note el lector la cercana vinculación con la excesiva onerosidad en la prestación.
} 
na fe ha sido valorada por la jurisprudencia como una circunstancia que da lugar al incumplimiento del contrato, por ende, de ella puede derivarse la resolución del contrato, la condena al cumplimiento o el resarcimiento del daño sea por violación del principio en la etapa precontractual, como por los daños que tales transgresiones generen en el desarrollo del contrato mismo." ${ }^{44}$-el subrayado es nuestro-.

En un sentido similar se pronuncia Eugenio Valladares, refiriéndose a la legislación española, al señalar que:

"(...) si de un modo tácito o implícito, las obligaciones contractuales de las partes, por disposición expresa del art. 1258 del CC, van más allá de lo expresado, extendiéndose a ese contenido obligacional dimanante no de la letra del contrato, sino de la buena fe, y si, al mismo tiempo, el art. 1101 del CC establece que la responsabilidad contractual se origina de cualquier modo en que se contravenga el tenor de la obligación -que no el tenor del contrato-, pareciera que la solución más armónica con la regulación del Código Civil es entender que la inobservancia del contenido obligacional implícito constituye incumplimiento del contrato, engendrándose la respectiva responsabilidad civil contractual en la medida en que haya daño." ${ }^{145}$-El subrayado es nuestro-.

En línea con lo anterior, Arturo Solarte sostiene que la desatención de los deberes secundarios de conducta deberá de tratarse como un supuesto de incumplimiento contractual o cumplimento defectuoso si el deber secundario tiene una vinculación directa con la ejecución de obligación del correspondiente negocio jurídico; sin embargo, si dicha relación es lejana correspondería aplicar las reglas de la respon- sabilidad extracontractual ${ }^{46}$. Por ejemplo, en un contrato de mandato, si se incumpliera el deber secundario de fidelidad - por contratar en contra de los intereses del mandante- sería posible considerar este hecho como un supuesto que permita la resolución, pues sería tratado como una obligación directamente vinculada con las obligaciones. En el caso de la renegociación, es innegable su extrema cercanía con la ejecución de la prestación.

Por las razones antes expuestas, soy de la opinión que el incumplimiento de los deberes secundarios de conducta en general, y del deber de renegociación en situaciones de desequilibrio fundamental de la relación sinalagmática en particular — sea por rechazo de la renegociación o por realizarla de forma deshonestaes un supuesto de incumplimiento contractual que habilita el ejercicio del derecho de resolución contractual.

\section{CONCLUSIONES}

Podemos señalar que el principio de buena es un principio general del Derecho que afecta a las partes durante todo el iter contractual, siendo un criterio orientador de conductas que exige de las partes un comportamiento diligente y, además, es un límite a la autonomía privada el cual evita que las partes puedan realizar acciones que dañen a su contraparte de forma contraria al más elemental sentido de justicia.

Como parte de los efectos del principio de buena fe las partes están obligadas al cumplimiento de deberes especiales, denominados deberes secundarios de conducta, aun cuando dichos deberes no hubieran sido expresamente incluidos en el documento contractual, pero que son integradas al programa negocial, en tanto fuente heterónoma.

\footnotetext{
44. Martha Neme Villarreal, Op. Cit., 107.

45. Eugenio Valladares Bonet, Op. Cit., 80-81

46. Arturo Solarte Rodríguez, Op. Cit., 312.
} 
Uno de estos deberes secundarios de conducta es el deber de renegociación de los contratos, el cual nace cuando ocurren algunos supuestos:

a) Fractura del equilibrio sinalagmático, sea por dos vías:

i. Por el incremento de la prestación; o,

ii. Por el decremento de la contraprestación.

b) Que esa fractura sea consecuencia de la situación externa, no propia del negocio, pues eso es propio del riesgo asumido por las partes.

c) El desequilibrio debe estar referido al elemento objetivo de la relación contractual, y no debe de referirse a situaciones subjetivas. Atender a esto sí podría llevarnos a desatender la propia razón del contrato, el cual es el establecimiento y asignación de riesgos entre las partes. d) Que la exigencia de cumplimiento cause un daño intolerable.

e) Inexistencia de un régimen de asignación de riesgos y responsabilidades sobre el particular.

El incumplimiento del deber de renegociación tiene la calidad de incumplimiento contractual y, por ello, habilitaría la resolución contractual ante la negativa de renegociación, o ante una renegociación contraria al espíritu de la buena fe.

Sin embargo, a fin de poder determinar si el deber de renegociación resulta aplicable al caso particular, será menester el correcto uso de los criterios hermenéuticos para comprender cuál es el régimen de asunción de riesgos y responsabilidades que han asumido las partes, el cual no puede ser contravenido. 